\title{
Redes intelectuais, internacionalização e regionalização acadêmica: uma abordagem a partir do contexto latino-americano
}

\author{
Intellectual networks, internationalization, and academic regionalization: \\ an approach through the latin american context
}

\author{
Cláudia Battestin \\ Benjamin Panduro Munhoz ${ }^{* *}$ \\ Miguel Ângelo Silva da Costa ${ }^{* * *}$
}

\section{Resumo}

O intuito deste artigo é apresentar, por meio de uma pesquisa bibliográfica, um panorama parcial sobre as redes intelectuais e de internacionalização no contexto da América latina, buscando pensar como essas ocorrem em tempos transitórios em que tudo muda de forma acelerada no âmbito político, econômico e, sucessivamente, nas políticas públicas para a educação. Contemporaneamente, tanto no Brasil como fora dele, os temas recorrentes ocupam cada vez mais espaço nas instituições de ensino e na agenda pública, tornando um desafio constante pensar esses processos com espaços e demandas diferentes. O campo de discussões é amplo e, com efeito, nele se engendram distintos desafios. Debater, portanto, o papel das redes intelectuais no processo de internacionalização acadêmica a partir do contexto latino-americano é o principal objetivo deste artigo.

Palavras-chave: América Latina. Internacionalização e regionalização acadêmica. Redes intelectuais.

\section{Abstract}

This paper aims to present a partial panorama over the intellectual and internationalization networks in the context of Latin American by means of a bibliographical research. It is investigated how they occur in transitional times in which everything changes in an accelerated way in the political, economic and successively in the public policies for education. Contemporaneously, both in Brazil and elsewhere, recurrent themes occupy more and more space in educational institutions and the public agenda, making it a constant challenge to think of these processes with different spaces and demands. The field of discussions is broad and, in fact, engender different challenges. Debate, therefore, the role of intellectual networks in the process of academic internationalization from the Latin American context is the main objective of this article.

Keywords: Latin America. Internationalization and academic regionalization. Intellectual networks.

Recebido em: 12/09/2016 - Aprovado em: 10/12/2016

http://dx.doi.org/10.5335/rep.v24i1.6988

Professora do Programa de Pós-Graduação em Educação da Universidade Regional Integrada do alto Uruguai e das Missões, URI-Campus de Frederico Westphalen. Doutora em Educação pela Universidade Federal de Pelotas (UFPel). E-mail: battestin@uri.edu.br

** Professor na Faculdade de Filosofia da Universidade de Colima, México. Doutor em Ciências Sociais pela Universidad de Colima, México. E-mail: majaramonda@yahoo.com.mx

*** Professor do Programa de Pós-Graduação em Educação da Universidade Regional Integrada do Alto Uruguai e das Missões, URI-Campus de Frederico Westphalen. Doutor em História pela Universidade do Vale do Rio dos Sinos (Unisinos).E-mail: migguelcosta@gmail.com 


\section{Introdução}

O poeta inglês John Donne declarou "no man is an island". De fato, o homem não é mais uma ilha! A expressão pode, efetivamente, ser associada ao contexto contemporâneo de produção de conhecimento nos mais variados campos de saber. Isso significa dizer que o conhecimento não é construído isoladamente, ou, conforme bem observou Bernardete Gatti, o pesquisador não mais trabalha sozinho, tampouco produz nessa condição. Mais do que isso, a autora afirma que "a intercomunicação com pares [...] constitui hoje uma condição essencial à realização de investigações científicas e ao avanço dos conhecimentos" (2005, p. 124).

Na mesma direção, Renato Balancieri (2005) salienta que a colaboração científica melhora o resultado e maximiza o potencial da produção de conhecimento, visto que amplia o repertório de abordagens e ferramentas que advém do intercâmbio de informações e da fertilização cruzada da formação de redes intelectuais. Todavia, é possível afirmar, com certo grau de convicção, que, na trama das redes de sociabilidade acadêmica, o protagonismo intelectual se configura na esteira de tensões próprias à atmosfera epistemológica de cada campo de atuação. Além disso, segundo Chaimovich (2000, p. 134), não seria nenhum exagero considerarmos que o protagonismo intelectual também se configura na esteira de tensões entre a liberdade do pesquisador e a necessidade social do conhecimento por ele produzido.

Não à toa, contemporaneamente, o processo de internacionalização e de colaboração científica ocupa espaços relevantes na pauta do debate acadêmico. Todavia, conforme salientou Thiago Marrara (2007, p. 247) esse debate não pode ser descolado das políticas de internacionalização que emergem tanto da alta Administração Pública (Ministérios, Secretarias e agências ligadas à educação, ciência e tecnologia), como, também, das próprias Instituição de Ensino Superior (IES). Além disso, não pode prescindir de um esclarecimento prévio acerca dos objetivos institucionais e acadêmicos que as permeiam.

Grosso modo, quando se fala em internacionalização acadêmica, de imediato e, até por motivos óbvios, nos vem a noção de tornar-se internacional academicamente. Mas o que, efetivamente, significa tornar-se internacional academicamente? Se pensarmos no viés da área da Educação, na esteira dos parâmetros definidos pela Coordenação de Aperfeiçoamento de Pessoal de Nível Superior (Capes), perceberemos que, as demandas e os questionamentos andam lado a lado... Nessa mesma direção, também poderíamos indagar qual o sentido das redes intelectuais no processo de internacionalização? Com que regiões/ países dialogamos de modo efetivo academicamente? E, ainda, se desejarmos verticalizar/ refinar um pouco mais o repertório de reflexões, poderíamos também pensar sobre o conteúdo e os limites da internacionalização acadêmica na área da Educação? 
Evidentemente, responder essas questões no espaço de um artigo não resta tarefa tão simples. Principalmente se levarmos em conta as especificidades próprias de cada área de produção de conhecimento. Porém, cremos que tais questões oferecem um bom horizonte de reflexão para problematizarmos as redes de internacionalização acadêmica no contexto latino-americano, principal objetivo deste artigo.

\section{A dimensão da internacionalização na América Latina}

A internacionalização na América Latina deve ser concebida enquanto um processo dinâmico em que as instituições envolvidas busquem dar respostas aos diferentes intercâmbios tecnológicos, epistemológicos, axiológicos e principalmente humanos, pois são esses que afetam o mundo globalizado.

Segundo Gacel Jocelyne (2000, p. 122-123), esta dinâmica implica nos planos de desenvolvimento nos quais as políticas da educação deixam de ser monolíticas, isto é, estruturadas somente em torno de um país ou, dentro do mesmo país, com uma só cultura ou etnia. Com efeito, as mudanças geradas pela globalização são tão complexas e diversas que as respostas e os questionamentos que surgem na investigação deixam ao descobrimento a necessidade urgente de melhorar a qualidade educativa, criar uma convivência pacífica entre os povos e preparar recursos humanos eficientes diante de um mundo competitivo e independente.

Estas respostas que buscamos mediante a investigação, podem ser unidimensionais ou excludentes, mas bem integrais e com uma clara ênfase na interdependência dos sujeitos ou instituições involucradas. A investigação no contexto Latino-americano se desenvolve, hoje em dia, em um ambiente mundial caracterizado pela preponderância do fator econômico sobre outros espaços da vida humana; a tal ponto de propiciar uma asfixia das humanidades e de todas aquelas áreas que não impliquem de maneira direta em benefícios para o mercado global da ciência e da tecnologia. Em efeito, o sistema capitalista prioriza e sempre priorizará a acumulação, a busca de rentabilidade, a ganância, a produtividade e a competitividade, marcando a agenda política, social e educativa criada pelas demandas exigidas pelo sistema. No mesmo sentido, o acelerado desenvolvimento da ciência e da tecnologia obedecem, precisamente, a uma necessidade da sociedade atual de dar respostas às exigências do mercado, isto é, à produção, ao comércio, ao intercâmbio de bens produzidos e à acumulação de lucros gerados.

Já afirmava Martí (1891, p. 15-22) que vivemos, assim, tempos eclipsados pelo lucro, pela mercadoria e a rentabilidade, situação que impede de visualizarmos nossa América, com todas as suas pessoas, povos, culturas, diferenças e igualdades. Esta difusão universal alcança todos os confins do mundo, principalmente nas van- 
tagens, na sobreposição dos fatores econômicos aos valores humanos, prática que nos impede de olharmos para os nossos próprios problemas de investigação, para nossas próprias realidades e conjunturas regionais. Isso tem gerado problemas de enorme envergadura para a comunidade acadêmica Latino-Americana, pois mesmo que o desenvolvimento tecnológico (os meios de transporte e as tecnologias de informação) tenham propiciado uma impressionante proximidade entre culturas e pessoas, o balanço a favor do entendimento e da convivência harmônica entre elas, nem sempre é positivo. Ao contrário, em grande medida tem servido para a formação de blocos, tanto econômicos como culturais, que preservam os privilégios de países e grupos dominantes. Em outros termos, a concepção de rentabilidade de vida, tem gerado como efeito a polarização do mundo entre nações ricas e pobres, situações que extraviam o olhar das redes de investigação para a urgente questão que favorece o crescimento econômico e deixa de lado o fundamental, o humano, propriamente dito.

O sistema atual das redes de investigações Latino-Americanas, conforme afirma Samir (1997, p. 45), se assentam e fundamentam em uma perspectiva que não considera a força de trabalho humana. A obstinação por lucros cegou os olhos dos responsáveis, sejam estes atores políticos ou econômicos, de modo que a violência, os conflitos e a imposição de regimes alegadamente democráticos são características normais de nosso ambiente, carregados de discursos "perigosos" que apoiam publicamente a liberdade e a democracia. Essa situação, única, sociopolítica e econômica, contribui para a paralisia da crítica e da geração de visões alternativas; situações dolorosas e tristes, pois constituem o fundamento da investigação desde a América Latina. Um dos exemplos é a polarização social do nosso mundo agravada pela crise ambiental, um corolário de obstinação pela produção e acumulação do lucro, capaz de revelar o quão errado é o caminho do crescimento econômico, nos fazendo repensar sobre os estilos de vida gerados pela invenção das necessidades e consumo excessivo. Enquanto a escassez de recursos naturais é uma faceta a mais da desigualdade (os grupos desfavorecidos são os principais prejudicados) as medidas paliativas aplicadas para parar a deterioração, bem como, os pressupostos antropológicos que enfatizam o egoísmo e a lógica do domínio sobre os outros seres humanos e não humanos, precisam ser revistos. De um modo geral, a vida dos seres humanos na sociedade contemporânea é situada na alienação, uma vez que nem no trabalho, nem na recreação, as oportunidades para o pensamento, a autorreflexão e a análise da própria situação, são prioridades. As relações humanas mercantilizadas acabam sendo superficiais e com interesses e alternativas de convivência incessantemente de uma visão egocêntrica do mundo, dirigida ao "pessoal" com pouco sucesso e compromisso social. 


\section{Internacionalização acadêmica: desafios e percalços}

No Brasil, o debate acerca da internacionalização acadêmica é relativamente recente. E, em certa medida, conforme Clarissa Eckert Baeta Neves e Carlos Benedito Martins (2016, p. 116) ganhou maior espaço na agenda das preocupações de acadêmicos, gestores universitários e na política para o ensino superior sob o impacto da publicação dos rankings internacionais e da disseminação do conceito de world class universities.

Praticamente um slogan, a noção de universidade de "classe mundial" encontra eco na lógica do desenvolvimento de sistemas competitivos de ensino superior e pesquisa em esfera global. No entanto, como já sinalizou Philip Altbach (2007, p. 122), todo país deseja ter uma universidade de classe mundial, porém, ninguém sabe, efetivamente, definir o que seria uma. Todavia, na esteira do pensamento deste intelectual norte-americano, podemos inferir que uma universidade com status de classe mundial é aquela que possui padrão internacional de excelência, sobretudo no que diz respeito à pesquisa e ao ensino.

Por outro viés, esse padrão de excelência internacional não pode ser entendido de modo deslocado dos objetivos com que cada instituição busca internacionalizar-se. Nessa direção e, em diálogo com os apontamentos de Thiago Marrara (2007, p. 248), nos parece possível considerar dois aspectos inerentes a tal processo, os quais podem ser resumidos a uma hipótese de natureza predominantemente institucional e, outra, de natureza estritamente acadêmica.

Sob a perspectiva puramente institucional, a internacionalização pode ser encarada simplesmente como uma via para aquisição de renome internacional em benefício de uma dada Instituição. Entre outras formas, isso pode se materializar por meio da oferta de cursos internacionalmente populares, pela organização de eventos de porte internacional, ou ainda, pela atração de alunos e pesquisadores estrangeiros ou pelo processo de divulgação internacional de pesquisas realizadas por pesquisadores vinculados a essas IES. Especificamente, nessa perspectiva, a internacionalização coloca-se a serviço de uma espécie de marketing institucional animado por uma lógica meramente de mercado e, a partir da qual, as políticas das Instituições de Ensino Superior concentram-se na incansável busca por novos consumidores para seus serviços.

No entanto, essa mesma "moeda" também apresenta outra face e, neste sentido, também podemos pensar o processo de internacionalização como um dispositivo colaborativo a serviço da formação de docentes, pesquisadores e discentes, ou seja... com efeito, um instrumento potencialmente rico sob o ponto de vista do processo educacional no âmbito da graduação e da pós-graduação. 
Inscrita numa cultura de inovação em educação e ciência, a universidade pode se internacionalizar por meio da aquisição de valor ou dimensão internacional decorrente de sua capacidade de colaborar para o desenvolvimento científico em nível supranacional, seja pelas suas atividades de formação, seja pela qualidade e pelo impacto de sua pesquisa. Conforme Marrara afirma:

Esse tipo de internacionalização se realizaria tanto por atividades discentes (envolvendo mestrandos e doutorandos), quanto docentes, tais como estágios de pesquisas no exterior, participação em cursos e congressos internacionais, celebração de co-tutelas ou meras co-orientações de mestrado e doutorado. Além disso, ela dependeria da formação de centros de pesquisas internos ou em consórcio com outras IES, do oferecimento de cursos e da organização de debates de interesse comum de diversos povos, nações e regiões (2007, p. 248).

Pensar o processo de internacionalização acadêmica, também significa compreender o contexto a partir do qual ele se constituiu. Importante levar em conta as normas, os valores, a linguagem, as inovações científicas e os produtos de conhecimento gerados num ambiente de alta competividade, onde determinados países e empresas multinacionais dominam o campo de produção do conhecimento global. Empresas de tecnologia da informação, biotecnológicas e farmacêuticas, editores multinacionais, entre outros, dominam a nova comunidade internacional de conhecimento, assim como o processo de geração de novos produtos baseados no conhecimento e na tecnologia da informação.

No entanto, esta realidade é dispare se comparada com países/ regiões emergentes, cujo potencial de autonomia e de competição no mundo globalizado é infinitamente inferior. Pensar o conceito de internacionalização acadêmica, a partir do contexto latino-americano e, em diálogo com um cenário mundial marcado por dramáticas desigualdades entre as universidades, também implica pensar nos valores e na cultura de nossas sociedades. É preciso compreender o contexto e as influências que o conceito, ainda jovem, carrega devido às demandas e vigências que ainda estão fortemente influenciadas pelo colonialismo.

Conforme já observamos, há não mais do que duas décadas, o termo internacionalização esteve associado a uma "educação internacional". A internacionalização não é educação internacional. Por ora, é preciso, antes de internacionalizar nossas pesquisas e ideias, buscar desenvolver e sistematizar que tipo de internacionalização nossas universidades necessitam para desempenhar um papel de unificação local, associado à realidade e à demanda da cultura regional, aspectos históricos da região, prevalência econômica e expectativas de diálogo entre iguais e antagônicos no âmbito de comunidades acadêmicas.

$\mathrm{Na}$ ótica de Morosini (2006, p.14), se a internacionalização tem ocupado lugar de destaque nas agendas políticas e universitárias, com o objetivo de alcançar 
crescimento notório nas investigações institucionais, ela também precisa ser dimensionada no âmbito de nossas pesquisas, de nossos currículos, de nossos processos culturais, sobre o que, efetivamente, ela poderá contribuir para viabilizar a inclusão, a inserção, o diálogo e, principalmente, iniciativas sustentáveis capazes de serem lembradas enquanto um movimento de ética e coerência nos princípios estabelecidos.

A internacionalização não pode ser considerada um fim em si mesma e nem um meio para se alcançar algo, ela deve ser vista como um aprimoramento, uma aproximação, um diálogo e uma acolhida por meio de ações que envolvam valores e objetivos em comum. Vale lembrarmos que cada região geográfica, cada país, terá a sua própria realidade e agudeza sobre quais benefícios e quais riscos a internacionalização poderá gerar.

Segundo estudos realizados por John Hudzik:

La internacionalización de la educación superior no es un concepto nuevo, de hecho tanto académicos como estudiantes han cruzado fronteras internacionales durante siglos. Sin embargo, en las últimas décadas, nuevos y poderosos factores han intensificado las dimensiones internacionales de la educación superior (2011, p. 02).

Para o autor, a internacionalização é um processo complexo, que pode abarcar todos os aspectos da educação superior, mas, se ela não for abrangente, corre o risco de ser a velha educação internacional concentrada no protagonismo do ocidente.

\section{Como pensar os processos de internacionalização}

De acordo com o Documento de Área da Educação (CAPES, 2013, p. 34-35) a internacionalização, na área da Educação, vem sendo desenvolvida em torno dos seguintes eixos:

a) o primeiro diz respeito à internacionalização realizada, principalmente por meio de publicações em livros e periódicos internacionais. Trata-se de resultados de pesquisas individuais ou de grupos de professores e pesquisadores publicados em periódicos internacionais de qualidade;

b) o segundo caracteriza a internacionalização como o desenvolvimento de pesquisas e outras atividades em rede que exigem maior envolvimento institucional do Programa e da IES. Dentre os produtos desse eixo estão também livros conjuntos e artigos em periódicos;

c) o terceiro diz respeito à atuação de pesquisadores e professores brasileiros em programa estrangeiros na qualidade de professores visitantes, assim como de pesquisadores estrangeiros nos programas no Brasil. Nessa última 
modalidade, ganham destaque os cursos de curta duração oferecidos nos programas de pós-graduação; e

d) o quarto eixo vem sendo desenvolvido por meio da cooperação internacional, envolvendo trânsito de alunos. Nessa linha, há cooperações com programas e países mais consolidados em termos de encaminhamento e recepção de alunos em programas na modalidade sanduíche. Paralelamente, é ainda valorizada a relação com países menos desenvolvidos, na forma de programas de cooperação para formação, em ações/ atividades desenvolvidas com África e alguns países da América Latina.

No Quadro 1, é possível observar o aumento gradativo de bolsas oferecidas para a modalidade de intercâmbio sanduiche, bem como, a preferência e escolha por regiões localizadas geograficamente ao norte, que, historicamente, sempre estiveram caracterizadas pelas elevadas condições de poder e acúmulo de riquezas.

Quadro 1 - Distribuição de bolsistas da Capes no exterior (2010 - 2013)

\begin{tabular}{|c|c|c|c|c|c|c|c|c|c|c|}
\hline País de destino & 2010 & $\%$ & 2011 & $\%$ & 2012 & $\%$ & 2013 & $\%$ & $\begin{array}{c}\text { Total } \\
\text { Período } \\
\end{array}$ & $\%$ total \\
\hline Portugal & 33 & 15,8 & 37 & 17,7 & 70 & 33,5 & 69 & 33,0 & 209 & 100,0 \\
\hline Espanha & 11 & 7,9 & 30 & 21,6 & 41 & 29,5 & 57 & 41,0 & 139 & 100,0 \\
\hline Estados Unidos da América & 16 & 15,1 & 21 & 19,8 & 32 & 30,2 & 37 & 34,9 & 106 & 100,0 \\
\hline França & 26 & 25,2 & 31 & 30,1 & 25 & 24,3 & 21 & 20,4 & 103 & 100,0 \\
\hline $\begin{array}{l}\text { Reino Unido da Grã-Bretanha } \\
\text { e Irlanda do Norte }\end{array}$ & 5 & 9,8 & 14 & 27,5 & 17 & 33,3 & 15 & 29,4 & 51 & 100,0 \\
\hline Argentina & 4 & 8,7 & 11 & 23,9 & 17 & 37,0 & 14 & 30,4 & 46 & 100,0 \\
\hline Canadá & 7 & 21,9 & 4 & 12,5 & 8 & 25,0 & 13 & 40,6 & 32 & 100,0 \\
\hline Alemanha & 6 & 23,1 & 6 & 23,1 & 8 & 30,8 & 6 & 23,1 & 26 & 100,0 \\
\hline Itália & 5 & 19,2 & 4 & 15,4 & 9 & 34,6 & 8 & 30,8 & 26 & 100,0 \\
\hline México & 1 & 9,1 & 0 & 0,0 & 3 & 27,3 & 7 & 63,6 & 11 & 100,0 \\
\hline Moçambique & 1 & 16,7 & 0 & 0,0 & 1 & 16,7 & 4 & 66,7 & 6 & 100,0 \\
\hline Timor-Leste & 0 & 0,0 & 0 & 0,0 & 2 & 50,0 & 2 & 50,0 & 4 & 100,0 \\
\hline Uruguai & 0 & 0,0 & 0 & 0,0 & 1 & 25,0 & 3 & 75,0 & 4 & 100,0 \\
\hline Bélgica & 0 & 0,0 & 0 & 0,0 & 1 & 33,3 & 2 & 66,7 & 3 & 100,0 \\
\hline Cuba & 1 & 50,0 & 0 & 0,0 & 0 & 0,0 & 1 & 50,0 & 2 & 100,0 \\
\hline Irlanda & 0 & 0,0 & 0 & 0,0 & 0 & 0,0 & 2 & 100,0 & 2 & 100,0 \\
\hline Suíça & 0 & 0,0 & 1 & 50,0 & 1 & 50,0 & 0 & 0,0 & 2 & 100,0 \\
\hline Austrália & 0 & 0,0 & 0 & 0,0 & 1 & 100,0 & 0 & 0,0 & 1 & 100,0 \\
\hline Chile & 0 & 0,0 & 0 & 0,0 & 0 & 0,0 & 1 & 100,0 & 1 & 100,0 \\
\hline Colômbia & 0 & 0,0 & 0 & 0,0 & 0 & 0,0 & 1 & 100,0 & 1 & 100,0 \\
\hline Dinamarca & 0 & 0,0 & 0 & 0,0 & 1 & 100,0 & 0 & 0,0 & 1 & 100,0 \\
\hline Luxemburgo & 0 & 0,0 & 0 & 0,0 & 0 & 0,0 & 1 & 100,0 & 1 & 100,0 \\
\hline Nova Zelândia (Aotearoa) & 1 & 100,0 & 0 & 0,0 & 0 & 0,0 & 0 & 0,0 & 1 & 100,0 \\
\hline Países Baixos (Holanda) & 0 & 0,0 & 0 & 0,0 & 0 & 0,0 & 1 & 100,0 & 1 & 100,0 \\
\hline Suécia & 0 & 0,0 & 0 & 0,0 & 0 & 0,0 & 1 & 100,0 & 1 & 100,0 \\
\hline
\end{tabular}

Fonte: elaboração dos autores com base em dados do Sistema de Informações Georreferenciadas da Capes. 
Diante desse percurso e trajetória, a educação brasileira e latino-americana precisa liberar-se das amarras e das influências externas, afastando-se dos conceitos neocoloniais que ainda carregam visões diferentes, incapazes de orientar nossa percepção de mundo. Pensar em algumas ações pode ser uma saída viável para as instituições educativas. Nesse intuito, pensamos em estratégias e possibilidades...

- Pensar a desinternacionalização. Desinternacionalizar é pensar ao contrário, rever os antigos preceitos, as antigas práticas tidas como certas. É preciso sair do padrão quantitativo e ir ao encontro de estratégias para aperfeiçoar e melhorar a qualidade do ensino e das investigações científicas, considerado aqui, qualitativo. A internacionalização não exige e não estabelece uma relação entre os países, mas, sim, entre as culturas, as histórias, as aproximações e similaridades em comum, seja ideológica ou utopicamente.

- Redes de internacionalização solidárias. Implica em estabelecer relações horizontais de cooperação e colaboração universitária, ou seja, um espaço capaz de produzir o diálogo e o pensamento crítico por meio de uma autonomia, uma vez que a universidade é um espaço de construção do conhecimento. Para o chileno Eduardo Devés, as redes de internacionalização sempre existiram, e nós: "Debemos referirnos a las redes, tanto a aquellas que nosostros constituímos como también a la manera em que nuestro trabajo se inserta dentro de um que hacer histórico de largo plazo. Nuestras redes son producto de redes anteriores" (2006, p. 14). O autor nos lembra que sempre tivemos relações de internacionalização com outros países por mieo de correspondências, diálogos e viagens, no entanto: "Para más Latinoamerica tiene la gran particularidad de que el intelectual casi nunca podria sobrevivir de su creacion bibliografica y por ello la tentacion de involucrarse directamente en la tarea politica siempre há estado latente y a veces era casi un dictado de superviviencia” (2006, p. 15). No entanto, a rede solidária só será possível de ser vivida por meio de projetos e construções a largo prazo, tanto que, segundo Albach y Teichler (2001) a reciprocidade, a confiança e a transparência ocorrem a partir da cooperação, colaboração e aprendizagem de uma compreensão mútua.

- Pensar ampliação e integração linguística. Para as universidades, é complexo pensar a configuração do conceito de internacionalização na América Latina, uma vez que o comprometimento dos docentes passa a ser uma configuração primordial no diálogo e nas interfaces entre a integração dos idiomas. As universidades devem pensar e adotar práticas e políticas linguísticas capazes de favorecer e facilitar a comunicação entre as fronteiras geográficas e do conhecimento, esse seria um aspecto relevante para a inte- 
gração e a identidade coletiva. Porém, deveremos levar em consideração que os idiomas português e espanhol não são exclusividade latinoamerica, pois os idiomas indígenas se somam e ampliam na medida em que observarmos a nossa diversidade cultural e competência intercultural no marco e domínio conceitual e interpretativo de nossos contextos socioculturais.

\section{Desafios futuros}

Os desafios para as redes latino-americanas, nesse cenário, são grandiosos. Eles não podem ser resolvidos desde uma disciplina, exigem esforços conjuntos para ver o mundo como um sistema que funciona de maneira sistemática e, portanto, precisa ser estudado de forma interdisciplinar. Frente a esse dever de analisar a realidade com sua complexidade e capacidade crítica, é urgente e necessário em situações de desigualdade, opressão, violência e destruição, ter um olhar sensível para a mudança e para a inserção social. Consolidar redes de pesquisas na América Latina consiste em reconhecer a desumanização do estado das coisas, de modo que a partir dos fundamentos de base epistemológica, antropológica e ética possamos promover novas formas de viver, ver e pensar o mundo, promovendo modelos de organizações sustentavelmente viáveis para o futuro.

Assim, o multiculturalismo torna-se uma ocasião para enriquecer a dialética que vai continuamente de si para o que pertence ao outro, do particular para o universo, valores locais aos exteriores e vice-versa. O reconhecimento do valor das diferentes culturas e da própria diversidade cultural exige pressupostos básicos de ordem humana capaz de atualizar, ampliar e fortalecer cada humano como um fim e nunca como um meio. A mesma regra serve para o respeito, para a autonomia dos indivíduos e dos povos, também, para definir e realizar os próprios projetos de vida e de desenvolvimento humano como parte integrante da natureza e do valor da diversidade natural a cultural.

Enquanto isso, as redes de pesquisa da América Latina, devem procurar ganhar a atenção daqueles que não estão convencidos do seu interesse teórico e prático do bem-estar social; a fim de operar como um excelente catalisador para uma ordem social que atenda às necessidades regionais de comunidades. No olhar de Panduro (2008, p. 16-25), os trabalhos de pesquisa com pouco ou nenhum contato com outras disciplinas e contextos reais da vida cotidiana devem ser vistos como trajeto de informação privilegiada. 


\section{Referências}

ALTBACH, Philip G. Globalization and the university: realities in an unequal world. In: FOREST, James J. F.; ALTBACH, Philip G. (Ed.). International Handbook of Higher Education. [S.1.]: Springer Publishers, 2007. p. 121-139.

ALTBACH, Philip G.; TEICHLER, Ulrich. Internationalization and Exchanges in a Globalized University. Journal of Studies in International Education, v. 9, n. 1, 2001.

BALANCIERI, Renato et al. A análise de redes de colaboração científica sob as novas tecnologias de informação e comunicação: um estudo na Plataforma Lattes. Ciência da Informação, Brasília, v. 1, n. 34 , p. $64-77$, jan. 2005.

CAPES - COORDENAÇÃO DE APERFEIÇOAMENTO DE PESSOAL DE NÍVEL SUPERIOR. Diretora de Avaliação. Documento de área 2013. Área de avaliação: Educação. Coordenadora de área: Clarilza Prado de Sousa. 2013. [S.I.] Disponível em: <https://www.capes.gov.br/images/stories/download/avaliacaotrienal/Docs_de_area/Educa\%C3\%A7\%C3\%A3o_doc_area_e_ comiss\%C3\%A3o_21out.pdf>. Acesso em: 28 ago. 2016.

CHAIMOVICH, Hernan. Brasil, ciência, tecnologia: alguns dilemas e desafios. Estudos Avançados, São Paulo, v. 14, n. 40, p. 134-143, dez. 2000.

DEVES, Valdés Eduardo. Redes intelectuales en América Latina. Chile: Colección Idea, 2007.

GACEL, Jocelyne. La dimensión internacional de las universidades mexicanas. Educación Superior y Sociedad, Universidad de Guadalajara, v. 11, n. 1 y 2, p. 121-142, 2000.

GATTI, Bernardete A. Formação de grupos e redes de intercâmbio em pesquisa educacional: dialogia e qualidade. Revista Brasileira de Educação, n. 30, p. 1-2, dez. 2005.

HUDZIK, John. Internacionalización integral del concepto a la acción. 2011. Disponível em: <http://www.nafsa.org/_/File/_/cizn2011_execsummary.pdf>. Acesso em: 7 ago. 2016.

MARRARA, Thiago. Internacionalização da pós-graduação: objetivos, formas e avaliação. Revista Brasileira de Pós-Graduação, v. 4, p. 245-262, 2007.

MARTÍ, José. Nuestra América. La Revista Ilustrada de Nueva York, 1 de enero de 1891.

MOROSINI, M. C. Estado do conhecimento sobre internacionalização da educação superior conceitos e práticas. Revista Educar, Curitiba, n. 28, p. 107-124, 2006.

NEVES, Clarissa Eckert Baeta; MARTINS, Carlos Benedito. Ensino superior no Brasil: uma visão abrangente. In: DWYER, Tom et al. Jovens universitários em um mundo em transformação: uma pesquisa sino-brasileira/organizadores. Brasília: Ipea/ Pequim: SSAP, 2016. p. 95-124.

PANDURO, Benjamin. El sujeto social y trá co de información privilegiada. En: Memorias del XX Coloquio Sobre la Enseñanza de la Filosofía. CMPF, Zacatecas, Noviembre 2008.

SAMIR, Amin. Los desafíos de la mundialización. México: Siglo XXI, 1997. 